\title{
The Risk of a Shod and Unshod Horse Kick to Create Orbital Fractures in Equine Cadaveric Skulls
}

\author{
Rahel Joss ${ }^{1}$ Fabio Baschnagel ${ }^{2}$ Stefani Ohlerth ${ }^{3}$ Gabor Piskoty ${ }^{2}$ Anton Fürst ${ }^{1}$ Andrea S. Bischofberger ${ }^{10}$ \\ ${ }^{1}$ Equine Department, Vetsuisse Faculty, University of Zürich, Zurich, \\ Switzerland \\ 2 Mechanical Systems Engineering Laboratory, Empa, Swiss Federal \\ Laboratories for Materials Science and Technology, Dübendorf, Switzerland \\ ${ }^{3}$ Section of Diagnostic Imaging, Vetsuisse-Faculty, University of \\ Address for correspondence Andrea S. Bischofberger, PD Dr. med. \\ vet., PhD, Dipl. ACVS \& ECVS, Equine Department, Vetsuisse Faculty, \\ University of Zürich, Zurich 8057, Switzerland \\ (e-mail: abischofberger@vetclinics.uzh.ch).
}

Zurich, Zurich, Switzerland

Vet Comp Orthop Traumatol 2019;32:282-288.

\begin{abstract}
Objective The aim of this study was to compare the potential of an unshod and shod hoof to cause an orbital fracture in the event of a kick.

Materials and Methods Thirty-four equine cadaveric orbitae were exposed to a steel or horn impactor in a dropping test set-up. An impactor velocity of $7 \mathrm{~m} / \mathrm{s}$ was used for both materials. Testing was repeated on the same orbit at a velocity of $10 \mathrm{~m} / \mathrm{s}$ with the horn impactor if no damage occurred. A high-speed camera was used to analyse the impact process. Physical parameters (peak force and impact duration) were calculated based on quantitative video-tracking. Computed tomographic (CT) scans were generated and fracture configurations described.

Results At $7 \mathrm{~m} / \mathrm{s}$, the fracture probability was lower for horn (23.5\%) than for steel impactors $(70.6 \%, p=0.015)$. On CT-images, damage of the frontal, temporal,

Keywords

- horse kick

- computed tomography

- shoeing material

- temporomandibular joint

- orbital fracture zygomatic and lacrimal bones was detected. Furthermore, the orbital socket (17.2\%), the supraorbital foramen (34.5\%) and the temporomandibular joint (58.6\%) were involved. The frequency of affected orbital bones was not significantly different between fractures generated by steel and horn impactors, but the fracture severity was subjectively greater when fractures were generated by steel impactors.

Clinical Significance The orbital fracture probability was significantly higher when a kick of a shod versus unshod horse was simulated. This indicates that keeping horses unshod would decrease the injury risk of neighbouring horses when considering group housing systems.
\end{abstract}

\section{Introduction}

In horses, orbital fractures are often the consequence of a horse kick. ${ }^{1}$ They may also occur following collision with a stationary object or following rearing in a confined space. Blunt trauma often leads to orbital rim fractures. Due to their exposed position, the dorsal orbital rim and the zygomatic arch are often affected. Orbital socket fractures are more

(1) Andrea S. Bischofberger's ORCID is https://orcid.org/0000-00027623-8627.

likely to be the result of rearing and falling over backward or damaging the poll. ${ }^{1,2}$

The orbital rim is formed by the frontal bone (dorsally), lacrimal bone (rostrally), zygomatic bone (ventrally) and temporal bone (laterally). The orbital socket consists of several parts: the nasal wall formed by the frontal, lacrimal and presphenoid bones; the roof mainly formed by the frontal and the lacrimal bone and the ventral wall formed by the zygomatic and parts of the temporal bone. The periorbital fascia encloses the eye bulb, the optic nerve and the eye muscles.,4

(c) 2019 Georg Thieme Verlag KG Stuttgart · New York
DOI https://doi.org/ 10.1055/s-0039-1683368. ISSN 0932-0814. 
The incidence of fractures originating from kick injuries has increased as group housing has become very popular amongst horse owners in Europe. Approximately half of the injuries caused by a horse kick were reported to result in fissures and fractures. ${ }^{5}$ It has been assumed that a kick from an unshod horse results in a less severe injury than a kick from a shod horse. This assumption has recently been supported by an experimental study in equine long bones, investigating the influence of shoeing systems on the injury risk of a horse kick. ${ }^{6}$ To simulate the kick, a rigid body impactor with a weight of $2 \mathrm{~kg}$ and an impact speed of 8 to $12 \mathrm{~m} / \mathrm{s}$ was used. This configuration was shown to be a good representation of a real horse kick and resulting injuries. ${ }^{7}$ The fracture probability in equine radii and tibiae using a soft material (i.e. unshod hoof or shod hoof with polyurethane, $0 \%$ at $8 \mathrm{~m} / \mathrm{s}$ and 12.5 to $25 \%$ at $12 \mathrm{~m} / \mathrm{s}$ ) was much lower than those using a hard material (i.e. shod hoof with steel and aluminium, $75-81 \%$ at $8 \mathrm{~m} / \mathrm{s})^{6}{ }^{6}$

Equine orbital fractures are underreported in the veterinary literature. ${ }^{2,4}$ Studies investigating an experimental equine orbital fracture model or the influence of different shoeing materials on orbital fracture probability and configuration are lacking. Hence, the objectives of this study were to simulate the kick of a shod (steel) and unshod hoof (horn) on the equine orbit and to evaluate the involved bones and surrounding structures (supraorbital foramen, nasolacrimal duct and the temporomandibular joint) in equine orbital fractures as well as the fracture configuration. It was hypothesized that fracture probability is significantly lower with a horn impactor than with a steel impactor.

\section{Materials and Methods}

Of 24 Warmblood horses humanely destroyed at the Vetsuisse-Faculty, University of Zürich, Switzerland between April and September 2016, the skulls were dissected from the body at the level of the atlanto-occipital joint. The skulls were frozen at $-20^{\circ} \mathrm{C}$ for up to 6 months. Before the experiment, the skulls were thawed in water for 65 hours and then hung up to dry for 5 hours.
To account for the different head sizes, external skull measurements were obtained and recorded: skull length (nasal bone to occipital bone), skull width (distance between the medial canthi of the eyes) and orbit diameter (medial to lateral canthus of the eye). The skull age was estimated according to its teeth age. ${ }^{8}$ The skulls were prepared to mount them onto a purpose-built stand for the experiments ${ }^{9}$ ( -Fig. 1A). The skin was removed from the skull area surrounding the orbit to improve observation of fracture generation.

The heads were positioned on a purpose-built stand (-Fig. 1B) containing a ball joint, allowing an individual alignment of each head with a $46^{\circ}$ angle of the nasal bone to the horizontal and a $34^{\circ}$ angle to the side from the sagittal plane. The impactor hit the orbit in a perpendicular fashion and was centred on the highest point of the orbital rim (-Fig. 1C). The stand was bolted to a stationary steel table to prevent movement of the head after the impact. To simulate the kick of a shod and unshod hoof, exchangeable cylindrical impactor heads ( $5 \mathrm{~cm}$ long $\times 1.5 \mathrm{~cm}$ diameter) made of steel (S275, density: $7.87 \mathrm{~kg} / \mathrm{m}^{3}$, elastic modulus: $210 \mathrm{GPa}^{10}$ ) and horn (hoof wall, density: $1.23 \mathrm{~kg} / \mathrm{m}^{3}$, elastic modulus: 750 $\mathrm{MPa}^{6}$ ), respectively, were attached to the tip of the impactor. The different masses of the cylinders were balanced with additional weights attached to the end of the aluminium body of the impactor, resulting in a total weight of $2 \mathrm{~kg}$. A piece of skin was removed from the orbit and placed over the cylinder to account for the skin previously removed from the orbit. The same dropping facility as previously described was used. ${ }^{6,7}$ The impactor was guided on a rail, oriented perpendicular to the orbit and centred on the highest point of the orbital rim. Adjusting the dropping height of the impactor set the impact velocity.

An impact velocity for the tests had to be chosen, which allowed a clear differentiation between the fracture risk potential of either impactor materials. Previous studies have shown that this criterion is fulfilled if the fracture probability is 60 to $80 \%$ with the presumably more critical material (i.e. steel in this study). ${ }^{6,7}$ To define the adequate impact velocity, five skulls ( 10 orbits) served as a pilot study. Impact velocity was gradually increased from $6 \mathrm{~m} / \mathrm{s}$ to $9 \mathrm{~m} / \mathrm{s}$ with $1 \mathrm{~m} / \mathrm{s}$ increments and the presence of a fracture or
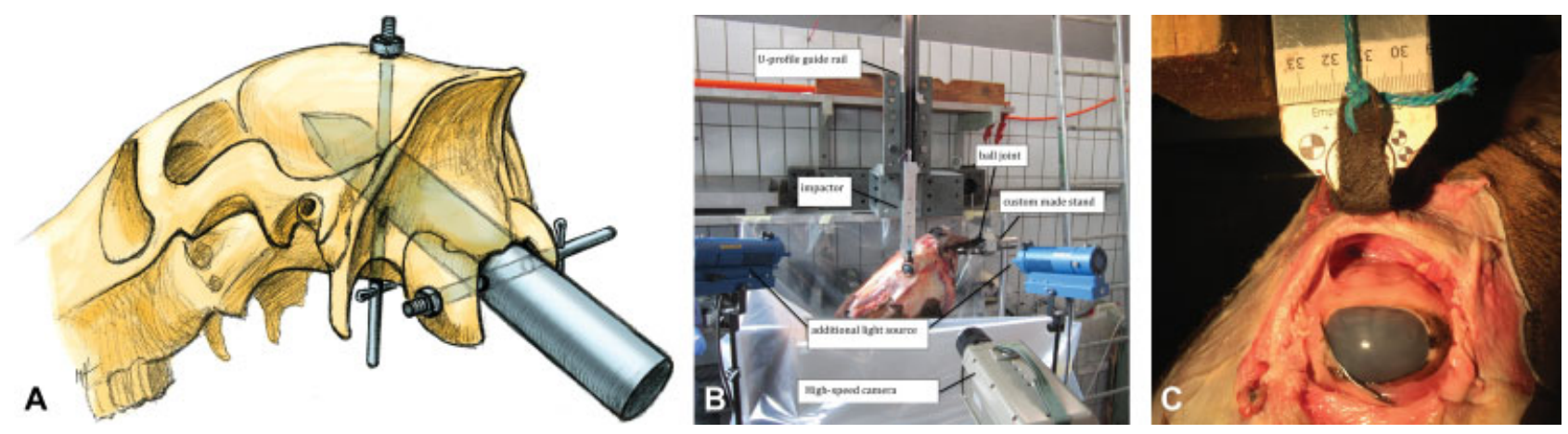

Fig. 1 (A) Schematic drawing showing a metal bolt (30 mm diameter) that was placed into the foramen magnum and fixed to the skull with two interlocking pins ( $8 \mathrm{~mm}$ diameter). The holes for the interlocking pins were drilled with a metal drill ( $8 \mathrm{~mm})$, one vertical going from the skullcap to the skull base in a sagittal plane and one horizontal going through the condyles of the occiput. (B) Image showing the custom-made stand with the mounted skull and the experimental set-up. (C) Close-up image of the left orbit with an impactor covered by a piece of head skin centred on the orbit. 
Table 1 Outcome of the pilot study. Impact velocities of the horn and steel impactor in meters per second ( $\mathrm{m} / \mathrm{s})$, outcome scaled in no fracture, fissure or fracture

\begin{tabular}{|l|l|l|l|l|l|}
\hline Pilot number & Material & $6 \mathrm{~m} / \mathrm{s}$ & $\mathbf{7} \mathrm{m} / \mathrm{s}$ & $\mathbf{8} / \mathbf{s}$ & $9 \mathrm{~m} / \mathrm{s}$ \\
\hline \multirow{4}{*}{} & Steel & No fracture & Fissure & Fracture & - \\
\cline { 2 - 6 } & Horn & No fracture & No fracture & Fissure & Fracture \\
\hline 2 & Horn & No fracture & No fracture & No fracture & Fracture \\
\hline \multirow{2}{*}{3} & Steel & Fracture & - & - & - \\
\cline { 2 - 6 } & Steel & Fissure & Fracture & - & - \\
\hline \multirow{2}{*}{4} & Steel & No fracture & Fracture & - & - \\
\cline { 2 - 6 } & Horn & No fracture & Fracture & - & - \\
\hline 5 & Steel & No fracture & Fracture & - & - \\
\hline
\end{tabular}

fissure (yes/no) was determined. Based on these results ( - Table 1 ), the starting velocity used in the main study was set to $7 \mathrm{~m} / \mathrm{s}$ for steel and horn ( $1 \mathrm{~m} / \mathrm{s}$ below the impact velocity used for the stronger long bones). ${ }^{6}$ At this velocity, with the horn impactor less than $25 \%$ and with the steel impactor $75 \%$ of the orbits fractured.

To obtain further information on the differences of the fracture probability and pattern between horn and steel, the horn impactor velocity was increased to $10 \mathrm{~m} / \mathrm{s}$ (doubling the kinetic energy at impact) for the follow-up experiments on the previously impacted (at $7 \mathrm{~m} / \mathrm{s}$ ) non-damaged orbits.

Due to evident damage to the orbit prior to testing (neoplasia, old orbital fracture), 2/24 skulls were excluded. Seventeen skulls were included in the main experiment. The right or left orbit was randomly assigned (by coin toss) to one impactor (either horn or steel). Following the impacts, the orbits were examined by palpation and macroscopic inspection and viewing the recordings of the high-speed camera to check if there was any evidence of fissure and/or fracture generation or not.

To characterize the impact process by quantitative results, the peak contact force $\left(F_{\text {peak }}\right)$ and the duration of the impact $\left(t_{\text {impact }}\right)$ on non-fractured heads were numerically derived from the recordings of a high-speed video camera (Phantom, V12.1; Vision Research, Ametek, Wayne, New Jersey, United States). The optical resolution was set to $400 \times 304$ or $368 \times 400$ pixels, depending on the size of the image section that had to be evaluated. This resulted in approximately 8.7 pixels $/ \mathrm{mm}$ and a frame rate of 34,000 frames per second (fps). This corresponds to a time resolution of $\Delta t=1 / \mathrm{fps}$ $=29.4$ microseconds $(\mu \mathrm{s})$. The position of the impactor over time $(y(t))$ and the fracture event were evaluated using computer-aided video-tracking (Matrox Design Assistant 4.0; Matrox Imaging, Dorval, Quebec, Canada) with an accuracy of $\Delta y= \pm 0.01 \mathrm{~mm}$. The impact velocity, $\mathrm{v}(\mathrm{t})$, was calculated by numerical differentiation of the displacement function in respect to time.

The contact force between the impactor and the bone ( $F$ $(t))$ was calculated based on Newton's law: $F(t)=m \times a(t)$, where $m$ is the mass of the impactor ( $2 \mathrm{~kg}$ ) and $a(t)$ is the deceleration of the impactor as a function of time, which was derived from the numerical differentiation of the velocity $v$ $(t)$. The time of first contact was defined when movement of the bone was first observed on the video recordings, whereas the time of reversal of the impactor was based on the measured velocity curve at $v(t)=0 \mathrm{~m} / \mathrm{s}$. The duration of the impact event $\left(t_{\text {impact }}\right)$ was defined as the time interval between these two events.

After the kicking experiments were completed, the skulls were examined by computed tomography (CT). Transverse continuous slices of the skulls were obtained in a helical mode from the incisors to the occipital bone with a 40-slice CT scanner (Sensation Open; Siemens Erlangen, Germany). Settings included: $140 \mathrm{KV}, 300 \mathrm{mAs}$, 1s tube rotation, a pitch of 0.55 and an increment of $1.2 \mathrm{~mm}$ and $3 \mathrm{~mm}$ slice collimation. The data were reconstructed to image series with $1.5 \mathrm{~mm}$ slice thickness using a medium-frequency image reconstruction algorithm (soft tissue) and a high-frequency image reconstruction algorithm (bone) respectively. Computed tomographic images were transferred to a workstation and reviewed by a board-certified radiologist (SO) and the first author (RJ) with dedicated software using multiplanar and 3D reconstruction modes (OsiriX Open Source Version 3.2.1; OsiriX Foundation, Geneva, Switzerland). A bone window was applied for the assessment (window width $=3,600$ Hounsfield units [HU]; window level $=600 \mathrm{HU}$ ).

The CT images were analysed as follows: affected side (left or right), fissure or fracture of the orbital rim (os lacrimale, os frontale, os temporale and os zygomaticus), fissure or fracture of the orbital socket, the sinuses, the supraorbital foramen, the nasolacrimal duct and the temporomandibular joint (yes or no). If one bone or more was fractured the overall fracture type (non-displaced, displaced or comminuted [ $>2$ fragments]) was defined. The CT findings were compiled in an Excel spreadsheet and all fractures were classified following a modification ( - Table 2) of the classification system by Buitrago-Téllez and colleagues developed for human midfacial/craniofacial fractures. ${ }^{11}$

Descriptive statistics were performed using a software program (BM SPSS Statistics, Version 19; Chicago, Illinois, United States). Numerical data were described by using means \pm standard deviations. Non-numerical data were described by using percentages and frequencies. The fracture probabilities were compared using Fisher's exact tests and 
Table 2 Modified classification system employed to classify the experimentally inflicted orbital fractures following evaluation of the computer tomography images

\begin{tabular}{|l|l|l|}
\hline Type & Group & Subgroup \\
\hline A: Non-displaced & $\begin{array}{l}\text { 1. Fracture of the } \\
\text { orbital rim }\end{array}$ & for $\mathrm{n}$ or $\mathrm{t}$ \\
\hline B: Displaced & $\begin{array}{l}\text { 2. Fracture of the orbital } \\
\text { rim and socket }\end{array}$ & $\mathrm{fn}$ or $\mathrm{ft}$ or $\mathrm{nt}$ \\
\hline $\begin{array}{l}\text { C: Complex } \\
\text { ( } \geq 2 \text { fragments) }\end{array}$ & $\begin{array}{l}\text { 3. Fracture of the orbital } \\
\text { (rim and socket) } \\
\text { and sinus }\end{array}$ & $\mathrm{fnt}$ \\
\hline
\end{tabular}

Abbreviations: $f$, supraorbital foramen; $n$, nasolacrimal duct; $t$, temporomandibular joint.

the physical parameters between materials using $t$-tests A $p$ value $<0.05$ was considered significant.

\section{Results}

The mean age of the horses was $10.8 \pm 4.0$ years. Skulls had a mean length of $59 \pm 2.6 \mathrm{~cm}$ and a mean width of $18.9 \pm 1.6 \mathrm{~cm}$. The mean orbital diameter was $6.3 \pm 0.5 \mathrm{~cm}$.

After being exposed to a steel impactor at $7 \mathrm{~m} / \mathrm{s}$, the fracture probability of the orbit was $70.6 \%$ (12/17). In five skulls, no fractures were noted macroscopically. In CT, 1/5 skulls had a fissure and 4/5 had no evidence of a fracture or a fissure. After being exposed to the horn impactor at $7 \mathrm{~m} / \mathrm{s}$, the fracture probability was $23.5 \%$ (4/17). For the 13 orbits that were re-exposed to a horn impactor at $10 \mathrm{~m} / \mathrm{s}$, the fracture probability was $53.8 \%$ (7/13). Six orbits showed no macroscopic fracturing signs; however, 5/6 (83.4\%) of these skulls showed multiple fissures in CT. Only one orbit showed no evidence of a fracture or a fissure. The fracture probability at $7 \mathrm{~m} / \mathrm{s}$ was significantly lower for the horn than that for the steel impactors $(p=0.015)$. - Fig. 2 shows a sequence of an orbit impacted with a steel impactor resulting in fracture.

For the evaluation of the physical parameters, only data from experiments that did not result in fractures were analysed to eliminate the above-mentioned effects of individual bone strength and stiffness. The actual velocities in the conducted experiments deviated slightly from the nominal target values of $7 \mathrm{~m} / \mathrm{s}$ and $10 \mathrm{~m} / \mathrm{s}$. The average measured actual speeds of the experiments with a horn impactor were $6.9 \pm 0.36 \mathrm{~m} / \mathrm{s}$ and $9.5 \pm 0.08 \mathrm{~m} / \mathrm{s}$, respectively. The experiments with a steel impactor were conducted at an average impactor speed of $6.7 \mathrm{~m} / \mathrm{s} \pm 0.38$. With the steel impactor, the average peak contact force $\left(F_{\text {peak }}\right)$ was 5,600 \pm 709 Newton $(\mathrm{N})$. With the horn impactor, the average $F_{\text {peak }}$ at $7 \mathrm{~m} / \mathrm{s}$ was $4,200 \pm 755 \mathrm{~N}$. The peak contact force $F_{\text {peak }}$ of the only experiment that did not result in bone damage at $10 \mathrm{~m} / \mathrm{s}$ was 7,200 N.

The average impact duration, $t_{\text {impact }}$, at velocities of $7 \mathrm{~m} / \mathrm{s}$ for the steel impactor was $1.79 \pm 0.30$ milliseconds (ms) and $2.44 \pm 0.58 \mathrm{~ms}$ for the horn impactor. The impact duration, $t_{\text {impact }}$, of the only experiment that did not result in bone damage at $10 \mathrm{~m} / \mathrm{s}$ was $1.51 \mathrm{~ms}$.

Combining all experiments at $7 \mathrm{~m} / \mathrm{s}$ and $10 \mathrm{~m} / \mathrm{s}$, orbital fractures were produced with 11/17 horn impactors and $12 / 17$ steel impactors, and orbital fissures were produced by $5 / 17$ horn impactors and $1 / 17$ steel impactors. The remaining orbits did not show any signs of fractures or fissures ([1/17 with horn] and [4/17 with steel]). While no involvement of the sinus or nasolacrimal duct was found, fractures were detected on the frontal ([11/11 with horn] and [12/12 with steel]) $(p=1.0)$, temporal ([5/11 with horn] and [9/12 with steel]) $(p=0.21)$, zygomatic ([4/11 with horn] and [4/12 with steel] $)(p=1)$ and lacrimal bone ([0/11 with horn] and [1/12 with steel]) $(p=1)$. Furthermore, also fractures of the orbital socket ([3/11 with horn] and [2/12 with steel]) $(p=0.64)$, supraorbital foramen ([5/11 with horn] and [5/12 with steel]) $(p=1)$ and the temporomandibular joint ([7/11 with horn] and [9/12 with steel]) $(p=0.67)$ were detected (-Figs. 3-5). No significant difference in the affected bones of the orbital rim (frontal, temporal, zygomatic and lacrimal bones) between the steel and horn impactor was found. Fracture frequencies and their classification are shown in - Figs. $3 A$ and B. Due to the low numbers of fractures $(n=4)$ generated with the horn impactor at $7 \mathrm{~m} / \mathrm{s}$, we cannot make a clear statement regarding the fracture severity compared with fractures generated by steel impactors.

\section{Discussion}

This study was aimed at investigating the probability of shod and unshod hooves to cause an orbital fracture in the event of

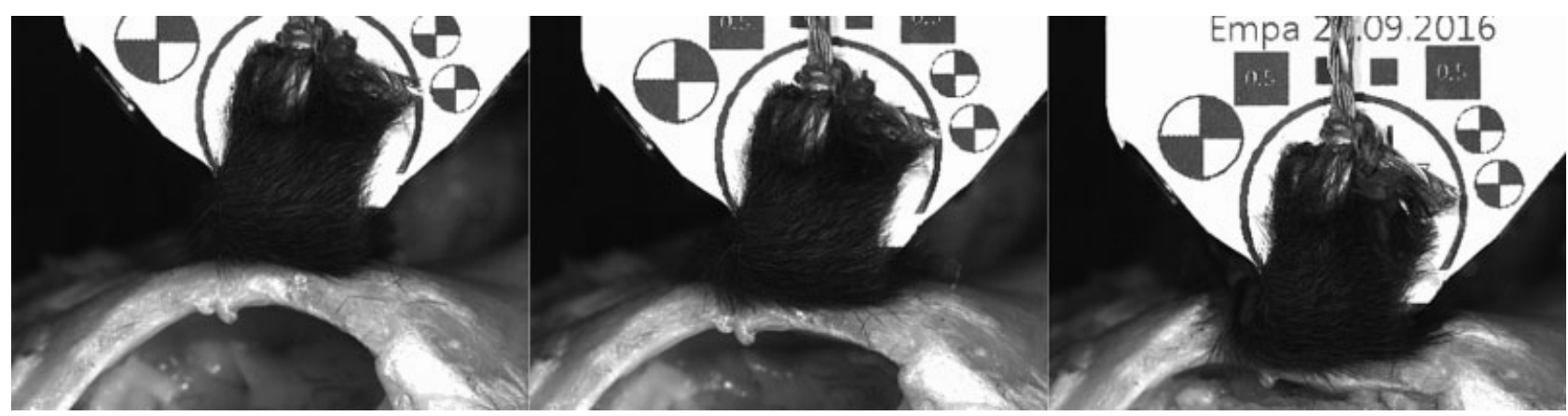

Fig. 2 Three typical consecutive images of a high-speed video showing an orbit impacted with a steel impactor ending in fracture (type $\mathrm{C} 1 \mathrm{f}$ ). The time point when the impactor first contacts the orbit (left image), deforming of the orbital rim (middle image) before the impact ends up in fracture (right image). 

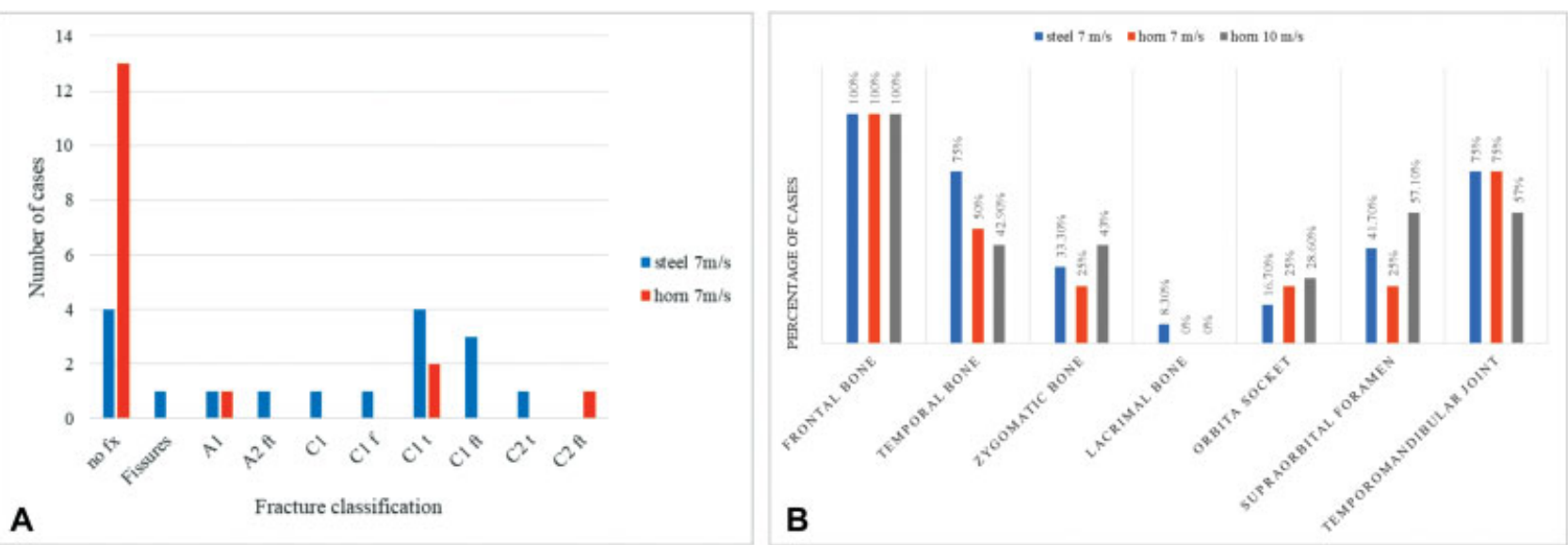

Fig. 3 (A) Bar chart showing the distribution of classified experimentally created orbital fissures and fractures divided into materials horn (red), steel (blue) at the velocity of $7 \mathrm{~m} / \mathrm{s}$. Classification was performed according to - Table 2 . The fracture severity is increasing from left to right, ranging from $\mathrm{A} 1$ (least severe) to C2 (most severe). (B) Bar chart showing the distribution of fracture frequencies of the affected bones of the orbital rim divided into materials and velocities (steel $7 \mathrm{~m} / \mathrm{s}$ in blue, horn $7 \mathrm{~m} / \mathrm{s}$ in red and horn $10 \mathrm{~m} / \mathrm{s}$ in grey).

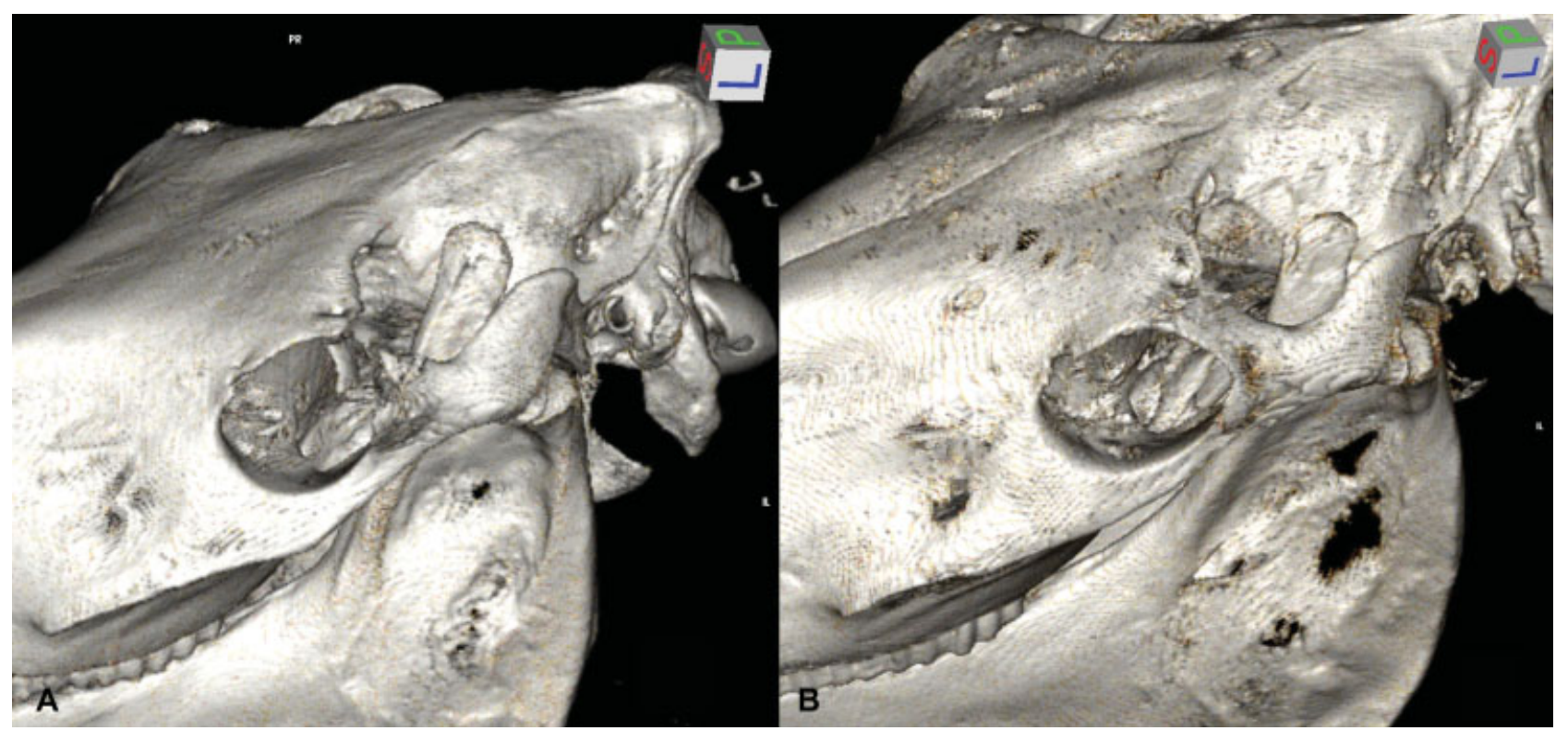

Fig. 4 (A) Three-dimensional reconstruction of a computed tomography (CT) image of a left orbit after impacting with steel at $7 \mathrm{~m} / \mathrm{s}$, resulting in a fracture of the frontal, temporal and zygomatic bones, as well as the orbital socket, supraorbital foramen and temporomandibular joint. (B) Three-dimensional reconstruction of a CT image of a left orbit after impacting with horn at $7 \mathrm{~m} / \mathrm{s}$, resulting in a fracture of the frontal, temporal and zygomatic bones as well as the orbital socket, supraorbital foramen and temporomandibular joint.

a kick. Probability of a fracture at $7 \mathrm{~m} / \mathrm{s}$ was three times higher in the shod versus the unshod kick experiment. Even after increasing the impactor speed of the unshod kick to 10 $\mathrm{m} / \mathrm{s}$ (thereby doubling the kinetic energy of the impactor at contact), the fracture probability of the shod kick at $7 \mathrm{~m} / \mathrm{s}$ was still 1.3 times higher. Based on these observations, the hypothesis that steel causes significantly more orbital fractures than horn was proven.

Since the impactor speeds were in the range of a real horse kick $^{6,7}$ the observed fractures were similar to clinical fractures described in earlier studies. ${ }^{12,13}$ It is reasonable to assume that the experimental kick conditions were similar to those encountered in nature. Hence, the prohibition of shoeing horses with steel shoes in grouped housing systems appears also justified for orbital fractures, similar to long bone fractures. ${ }^{6}$ To allow video imaging of the bone surface during the impact process but still closely simulating a life scenario, a piece of skin was placed over the impactor. The mitigating effects of the skin onto the fracture configuration need to be kept in mind when comparing this study to the long bone study, ${ }^{6}$ as this was not performed in the latter one.

Analysing the impact process captured by the high-speed camera revealed the following: the impact leads to a severe indentation of the orbital rim that can lead to bone failure. However, this indentation largely depends on the stiffness of the orbit. As this stiffness is governed by the geometry and structure of the bone and orbit, it is different for every skull. The event of damage to the bone is indicated by an abrupt 


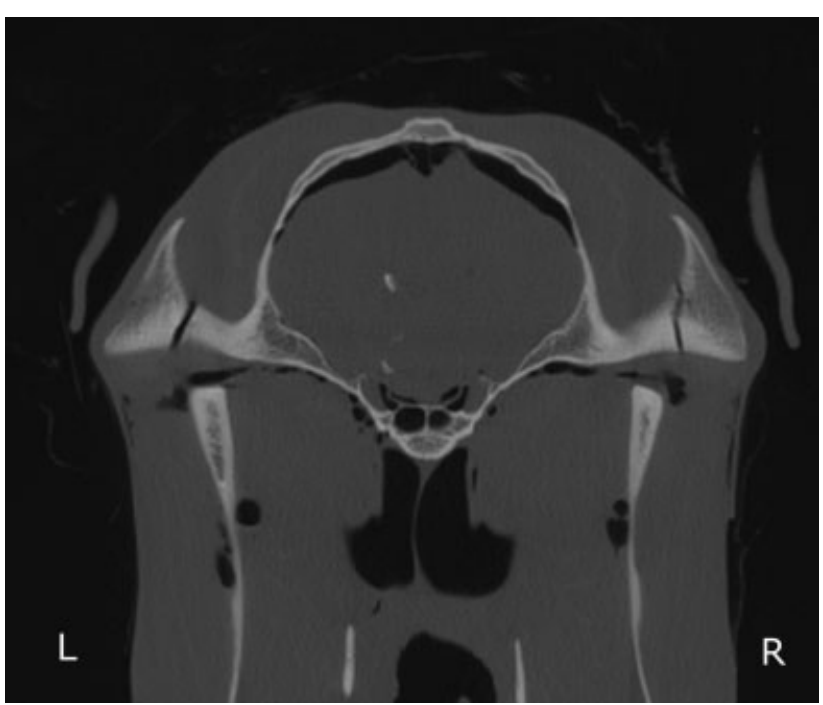

Fig. 5 Computed tomography image showing bilateral temporomandibular joint fractures after impacting with horn at $7 \mathrm{~m} / \mathrm{s}$ on the left side and impacting with steel at $7 \mathrm{~m} / \mathrm{s}$ on the right side.

jerk of the rim. If the strain limit of the bone is not exceeded and no fracture occurs, the orbit unfolds to its initial shape after the impact.

The $F_{\text {peak }}$ values were approximately 3.5 times lower than the values obtained in a previous study on equine long bones. ${ }^{6}$ This difference can be explained by the higher compliance of the bone (skull) in this study, judged from the video-recordings. This results in lower contact forces since the resistance to the impact is lower. The $30 \%$ higher contact forces with a steel impactor than with a horn impactor are in good agreement with the previous study. ${ }^{6}$ Similar to the peak contact forces, the impact durations varied between the two tested materials. Horn takes longer to decelerate to $0 \mathrm{~m} / \mathrm{s}$, resulting in a 1.36 time longer $t_{\text {impact }}$ than for steel. This difference between horn and steel is in good agreement with the literature, but the absolute values are 1.45 times higher than the literature values. ${ }^{6}$ The longer impact durations can also be explained with the higher compliance of the bone and its lower resistance to the impact, resulting in a smoother and hence slower deceleration of the impactor.

Conditions in the test set-up had to be realistic and well defined. Experimental studies simulating a horse kick have only been published for long bones so far. Hence, there was no literature available on how to fixate the head for the experiments without influencing the fracture occurrence and generation. Although not all fractures diagnosed with CT could be recorded with the high-speed camera, it is judged unlikely that the head fixation influenced the occurrence or generation of the obtained fractures. The freezing process, storage at $-20^{\circ} \mathrm{C}$ up to 6 months, and thawing are not expected to have had a significant effect on the biomechanical properties and the histological morphology of the orbits in this study. ${ }^{14-18}$

Fracture or fissure involvement of the temporomandibular joint was observed in overall 58.6\% (i.e. 1 fissure and 16 fractures out of 29, - Fig. 5) of the skulls with orbital fractures. Cases of orbital fractures involving the temporomandibular joint have been described previously. ${ }^{12,19}$ The determination of the percentage of true clinical orbital fractures involving the temporomandibular joint would require a retrospective study on naturally occurring orbital fracture configurations. However, clinicians should consider temporomandibular articulation injury such as fractures and fissures in orbital fractures.

In contrast to expectations and earlier assumptions by other authors, ${ }^{20}$ fracture involvement of the orbital socket was overall quite high $17.3 \%$ (5/29). In humans, early studies proposed that the responsible mechanism of fractures is a direct globe-to-wall contact. ${ }^{21}$ Meanwhile, there are two accepted theories on the mechanism of orbital blow-out fractures. ${ }^{22-25}$ The 'hydraulic theory' states that through blunt trauma to the soft tissues of the orbit, the intraocular pressure increases and results in fracture. ${ }^{24}$ The 'buckling theory' states that the fracture is a consequence of the transmitted buckling force via the orbital rim. ${ }^{26}$ Studies have shown that the hydraulic theory produces larger fractures with frequent herniation of the orbital contents compared with the buckling mechanism that produces smaller fractures without significant herniation. ${ }^{22,27}$ In horses, only the caudolateral and some ventral parts of the orbital contents are not embedded in the osseous orbit. ${ }^{3}$ In the authors' clinical experience, orbital herniation is seldomly observed and the fracture process analysed with the recordings of the high-speed camera more likely matches the 'buckling theory'.

In humans, there are various classification systems of midfacial/craniofacial fractures. ${ }^{28-31}$ In veterinary clinical practice, orbital fractures have not been classified yet. The modified classification system used in this study allows a comprehensive and detailed description of the orbital fracture configuration. The potential benefits of such a standardized classification system include improved interdisciplinary communication between veterinarians involved in the diagnosis and treatment of these fractures. Furthermore, such a system has the potential to analyse the outcomes of different therapeutic strategies. By defining the orbital region into three units (orbital rim, orbital socket and neighbouring sinuses), the fracture type and the involvement of specific structures (supraorbital foramen, temporomandibular joint or nasolacrimal duct), the severity of an orbital fracture may be assessed.

Some limitations of the present study need to be addressed. Due to the experimental set-up and the study time-plan, it was not possible to perform $\mathrm{CT}$ after the first horn impacts at $7 \mathrm{~m} / \mathrm{s}$. The orbits were only macroscopically examined and the highspeed videos were analysed. More fissures were detected with CT in skulls being exposed to a horn impactor twice $(7 \mathrm{~m} / \mathrm{s}$ and $10 \mathrm{~m} / \mathrm{s}$ ) than in skulls that were exposed to a steel impactor only once $(7 \mathrm{~m} / \mathrm{s})$. The authors cannot exclude the possibility that some fissures formed after the first impact with horn were not noted macroscopically, leading to failure in the second experiment. Nevertheless, it appears a minor drawback as the fracture probability of horn at $10 \mathrm{~m} / \mathrm{s}$ was still lower than for steel at $7 \mathrm{~m} / \mathrm{s}$.

This study showed that the orbit fracture probability is significantly higher when a kick of a shod versus unshod hoof is simulated. This indicates that keeping horses unshod, at least the hind limbs, would decrease the injury risk of 
neighbouring horses in group housing systems. In greater than half of the orbital fractures detected, an additional fracture of the temporomandibular joint was present, which should be kept in mind by clinicians treating such cases.

\section{Author Contribution}

Rahel Joss, Fabio Baschnagel, Stefani Ohlerth and Andrea S. Bischofberger contributed to conception of study, study design, acquisition of data and data analysis and interpretation. Gabor Piskoty and Anton Fürst contributed to conception of study, study design, and data analysis and interpretation. All authors drafted, revised and approved the submitted manuscript.

\section{Funding}

None.

\section{Conflict of Interest}

All authors report grants from Foundation pro Horse, Switzerland, during the conduct of the study.

\section{References}

1 Gerding JC, Clode A, Gilger BC, Montgomery KW. Equine orbital fractures: a review of 18 cases (2006-2013). Vet Ophthalmol 2014;17(Suppl 1):97-106

2 Hartley C, Grundon RA. Diseases and surgery of the globe and orbit. In: Gilger BC, ed. Equine Ophthalmology. 3rd ed. Ames Iowa: John Wiley \& Sons Inc; 2017:151-196

3 Wissdorf H, Otto B, Gerhards H. Nebenorgane des Auges. In: Wissdorf H, Gerhards H, Huskamp B, Deegen E, eds. Praxisorientierte Anatomie und Propädeutik des Pferdes. 3rd ed. Hannover: Schaper; 2010:91-111

4 Pierce KE, Townsend WM. Surgery of the globe and orbit. In: Auer JA, Stick JA, eds. Equine Surgery, 4th ed. St. Louis, MO: Elsevier/ Saunders; 2012:728-743

5 Derungs SB, Fürst A, Hässig M, et al. Frequency, consequences and clinical outcome of kick injuries in horses: 256 Cases (19922000). Wien Tierarztl Monatsschr 2004;91:114-119

6 Sprick M, Fürst A, Baschnagel F, et al. The influence of aluminium, steel and polyurethane shoeing systems and of the unshod hoof on the injury risk of a horse kick. An ex vivo experimental study. Vet Comp Orthop Traumatol 2017;30(05):339-345

7 Piskoty G, Jäggin S, Michel SA, Weisse B, Terrasi GP, Fürst A. Resistance of equine tibiae and radii to side impact loads. Equine Vet J 2012;44(06):714-720

8 Muylle S. Aging. In: Baker GJ, Easly J, eds. Equine Dentistry. 2nd ed. New York: Elsevier/Saunders; 2005:55-66

9 Gfrerer L, Jackson M, Fürst A, eds. Frakturkonfiguration der Mandibularfrakturen beim Pferd. Netzwerktagung; 2016; Avenches: Schweiz Archiv Tierheilk. (Fracture configuration of equine mandibular fractures. Network conference; 2016; Avenches: Swiss Archive of Veterinary Science)

10 Schweizer A. Formelsammlung und Berechnungsprogramm für Anlagenbau [homepage on internet]. 2007. [cited on 2018 February 12]. Available at: http://www.schweizer-fn.de/festigkeit/festigkeitswerte/stahl_start.php. Accessed February 12, 2018

11 Buitrago-Téllez CH, Schilli W, Bohnert M, Alt K, Kimmig M. A comprehensive classification of craniofacial fractures: postmor- tem and clinical studies with two- and three-dimensional computed tomography. Injury 2002;33(08):651-668

12 Blogg JR, Stanley RG, Phillip CJ. Skull and orbital blow-out fractures in a horse. Equine Vet J Suppl 1990;10(10):5-7

13 Caron JP, Barber SM, Bailey JV, Fretz PB, Pharr JW. Periorbital skull fractures in five horses. J Am Vet Med Assoc 1986;188(03): 280-284

14 Andrade MGS, Sá CN, Marchionni AM, dos Santos Calmon de Bittencourt TC, Sadigursky M. Effects of freezing on bone histological morphology. Cell Tissue Bank 2008;9(04):279-287

15 Linde F, Sørensen HCF. The effect of different storage methods on the mechanical properties of trabecular bone. J Biomech 1993;26 (10):1249-1252

16 Matter HP, Garrel TV, Bilderbeek U, Mittelmeier W. Biomechanical examinations of cancellous bone concerning the influence of duration and temperature of cryopreservation. J Biomed Mater Res 2001;55(01):40-44

17 Panjabi MM, Krag M, Summers D, Videman T. Biomechanical timetolerance of fresh cadaveric human spine specimens. J Orthop Res 1985;3(03):292-300

18 Pelker RR, Friedlaender GE, Markham TC, Panjabi MM, Moen CJ. Effects of freezing and freeze-drying on the biomechanical properties of rat bone. J Orthop Res 1984;1(04):405-411

19 McMaster M, Caldwell F, Gillen A, Hespel A, Budny P, Abarca E. Reconstruction of a complicated orbital depression fracture with medial wall and globe repositioning in a horse: a collaboration across disciplines and specialties. Vet Surg 2016;45(04):529-535

20 Brooks DE, Dan Wolf E. Ocular trauma in the horse. Equine Vet J 1983;15:141-146

21 Pfeiffer RL. Traumatic enophthalmos. Trans Am Ophthalmol Soc 1943;41:293-306

22 Ahmad F, Kirkpatrick NA, Lyne J, Urdang M, Waterhouse N. Buckling and hydraulic mechanisms in orbital blowout fractures: fact or fiction? J Craniofac Surg 2006;17(03):438-441

23 Bullock JD, Warwar RE, Ballal DR, Ballal RD. Mechanisms of orbital floor fractures: a clinical, experimental, and theoretical study. Trans Am Ophthalmol Soc 1999;97:87-110, discussion 110-113

24 Smith B, Regan WF Jr. Blow-out fracture of the orbit; mechanism and correction of internal orbital fracture. Am J Ophthalmol 1957; 44(06):733-739

25 Rhee JS, Kilde J, Yoganadan N, Pintar F. Orbital blowout fractures: experimental evidence for the pure hydraulic theory. Arch Facial Plast Surg 2002;4(02):98-101

26 Fujino T, Sugimoto C, Tajima S, Moribe Y, Sato TB. Mechanism of orbital blowout fracture. II. Analysis by high speed camera in two dimensional eye model. Keio J Med 1974;23(03):115-124

27 Waterhouse N, Lyne J, Urdang M, Garey L. An investigation into the mechanism of orbital blowout fractures. Br J Plast Surg 1999;52 (08):607-612

28 Fraioli RE, Branstetter BF IV, Deleyiannis FW. Facial fractures: beyond Le Fort. Otolaryngol Clin North Am 2008;41(01):51-76, vi

29 Ahmad Z, Nouraei R, Holmes S. Towards a classification system for complex craniofacial fractures. Br J Oral Maxillofac Surg 2012;50 (06):490-494

30 Bächli H, Leiggener C, Gawelin P, et al. Skull base and maxillofacial fractures: two centre study with correlation of clinical findings with a comprehensive craniofacial classification system. J Craniomaxillofac Surg 2009;37(06):305-311

31 Ong HS, Qatarneh D, Ford RL, Lingam RK, Lee V. Classification of orbital fractures using the AO/ASIF system in a population surveillance cohort of traumatic optic neuropathy. Orbit 2014; 33(04):256-262 